\title{
A social practice theory of learning and becoming across contexts and time
}

\author{
William R. Penuel, Daniela K. DiGiacomo, Katie Van Horne, Ben Kirshner \\ University of Colorado, United States \\ Article received 7 September / revised 9 August / accepted 12 September / available online 19 December
}

\begin{abstract}
This paper presents a social practice theory of learning and becoming across contexts and time. Our perspective is rooted in the Danish tradition of critical psychology (Dreier, 1997; Mørck \& Huniche, 2006; Nissen, 2005), and we use social practice theory to interpret the pathway of one adolescent whom we followed as part of a longitudinal study of interest-related learning. A social practice theory calls out the ways people pursue diverse concerns, become aware of new possibilities for action as they move across settings of practice, and learn as they adjust contributions to the flow of ongoing activity and to fit demands and structures of local institutions. It also highlights the ways that existing institutional structures of practice frame the choices people make about how and where to participate in activities. This perspective on learning is potentially transformative, in that it provides a way to promote equity by surfacing issues associated with linkages among settings of practice, networks of actors who support persons' movement across settings, and diversities in structures of practices that shape opportunities to learn and become.
\end{abstract}

Keywords: Social practice theory; learning; agency; equity 


\section{Introduction}

Education systems around the world are experimenting with different ways to prepare youth to participate in, and lead, the global "knowledge economy." In the United States, where we live, this has meant a push for higher quality science, technology, engineering, and math (STEM) learning opportunities, more STEM graduates from universities, and greater access to STEM learning for groups that have been historically excluded from quality schooling. Although the equity-related goals of expanding STEM access are laudable, we worry that too many STEM policies and educational interventions rest on flawed, inaccurate understandings of what it means to develop and sustain a learning pathway. Put briefly, where curriculum developers privilege narrowly defined maps of cognitive learning progressions required for deep understanding, we propose a more expansive view of pathways that embeds learning and development in the broader context of social practice. Ours is a social, materialist conception of pathways that has roots within the Danish school of critical psychology (Dreier, 1997; Mørck \& Huniche, 2006; Nissen, 2005).

Learning pathways unfold over time across multiple settings. The temporal dimension of learning is always situated within the evolution of broader social practices and institutions. As such, learning is part of persons" "changing participation in changing practices" (Lave, 1996, p. 150). The spatial dimension involves a form of movement of actors within and across the different social contexts of their lives (Gutiérrez, 2008). As practices evolve and spaces are reorganized, people pursue diverse and evolving concerns and imagine new possibilities for themselves, thereby becoming different people by gathering, adopting, and pursuing stances toward what they do and value (Dreier, 2008). At the same time, political borders and historically rooted but persistent inequities shape who people become and where they can move; for many, these constraints are experienced as disruptions and threats to their well-being and social worlds that must be actively managed (Gonzales, 2011; Mørck, 2010).

Historically and still today, research on learning has proceeded from a different set of assumptions about the nature of learning pathways. For example, many studies of learning in neuroscience and psychology focus on brief experiments that take place in a single setting (e.g., McDaniel, Agarwal, Huelser, McDermott, \& Roediger III, 2011). In education, where there is more research on complex classroom processes that unfold over time, few learning researchers have studied how these processes are embedded within changing social and political structures of schools and societies (Lave \& McDermott, 2002; Penuel, 2016). There is limited attention to how inequities are reproduced within educational systems through the production of failure, that is, by making educational success into a scarce resource and disproportionately identifying individuals from disenfranchised groups "disabled" or "failures" who should be held to account for their own plight (Lave, 1996; Varenne \& McDermott, 1998).

In this conceptual paper, we argue for social practice theory to guide the study of learning pathways across setting and time, presenting a case study analysis that illustrates how it might be applied to the study of learning over time and across settings. Social practice theory (Dreier, 1999, 2008; Holland \& Lave, 2009; Lave, 2012) emphasizes the importance of tracing pathways of participation across varied contexts and over time. We elaborate this theory in the context of a longitudinal study of students' interest-related learning. We argue that analyzing the visibility, continuities, and discontinuities of learning pathways from youth's own point of view provides a valuable framework for diagnosing inequity in access to participation in valued social practices. The assumption is that structures of practice present both constraints and possibilities for action to persons; the task of the analyst is to identify specific conditions that are relevant to the lives of persons in practice, what those mean to persons and practices, and the reasons for persons' actions (Jefferson \& Huniche, 2009; Mørck \& Huniche, 2006). 


\section{Studying learning pathways in social practices}

Social practice theory begins with the premise that people participate in multiple and variable social contexts. Participation is neither constant nor bound to a particular place: people "participate for longer or shorter stretches of time, on a regular or occasional basis and for various reasons in several contexts" (Dreier, 2008, p. 38). The name pathway captures the ideas that movement and direction are both important aspects of the temporal and spatial dimensions of participation in practice (Dreier), though social practice theory views these pathways in concrete, social, and material terms and not as idealized progressions (Penuel, 2016). Similarly, a learning pathway can be described in terms of how people move across borders between the familiar and the unfamiliar (Gutiérrez, 2008) and in terms of a telos, that is, the direction of movement or change (Lave, 1996). From the perspective of social practice theory, the movement and direction of learning is not chosen in isolation from available social and institutional structures, but in relation to them. As Dreier (2008) writes, people must "take into account the structuring of social practice into particular contexts with particular links and use those links in directing their trajectories [pathways] across them" (p. 38).

From the standpoint of social practice theory, the complexity and diversity of practices in which people participate is not necessarily a burden but is an enriching aspect of life. By moving across settings of social practice, people are able to pursue diverse concerns and become aware of new possibilities for action and arrangements for participation in practice (Dreier, 2008). In addition, they are confronted with dilemmas and contradictions that motivate change and learning (Engeström \& Sannino, 2010; Mørck, 2010). People learn by adjusting their contributions to activities to one another (O'Connor \& Allen, 2010) and to fit the demands and structures of local institutions (Dreier, 2009). People also learn by inventing new ways to participate in practice, molding it into new cultural forms through our participation (Calabrese Barton \& Tan, 2009; Gutiérrez, Baquedano-Lopez, \& Tejada, 2000).

Existing institutional structures of practice frame the choices people make about how and where to participate in activities. Directing their learning pathways requires that people distribute their engagement across different settings, according to the suitability of each setting's institutional arrangements for pursuing a particular concern and how the settings are linked to valued practices in other settings (Dreier, 2008). These institutional arrangements themselves vary with respect to roles and possibilities for action, requirements for access to those roles, and persistent patterns of privilege, exclusion, and marginalization (Lave \& McDermott, 2002). Any one institutional setting for participation, then, is both a place for learning and a connection point in a more spatially and temporally extended pathway.

For our analysis, then, we used social practice theory because it allowed us to make sense of youth's suspended participation alongside attending carefully to youth's oft-ambiguous relationship to contentious structures of practice and histories (Holland \& Lave, 2009). Social practice theory also demands that we pay "particular attention to differences among participants, and to the ongoing struggles that develop across activities around those differences" (Holland \& Lave, 2009, p. 5). In this respect, a social practice account differs in emphasis from what might emerge from an analysis of activity systems from a cultural-historical activity theory (CHAT) perspective, because the unit of analysis is persons in practice. In CHAT, the unit of both analysis and intervention is the activity system (Cole \& Engeström, 2006). At the same time, social practice theory has common roots with CHAT, in that both draw from accounts of human activity developed by Marx and Engels (Marx \& Engels, 1848/1998). In addition, both share a commitment to collaborative engagement of researchers with practice to expand possibilities for learning and movement across contexts (Gutiérrez, 2008; Gutiérrez \& Vossoughi, 2010; Jurow \& Shea, 2015; Mørck, 2010). ${ }^{1}$ 


\section{Supporting and studying science learning pathways: The case of Jerome}

A number of science education researchers have documented ways that youth are active participants in directing learning pathways in science in ways that are in close alignment with how Dreier (2008) characterizes peoples' efforts to distribute their engagements across settings (Bricker \& Bell, 2014; Crowley, Barron, Knutson, \& Martin, in press; Polman \& Miller, 2010). As Bell and colleagues (Bell, Tzou, Bricker, \& Baines, 2012) write, "science learners need to figure out how to adapt their abilities, interests, and identities across a diverse set of locations on a routine basis as they attempt to accomplish their goals or respond to the interests of other social actors" (p. 270). They further argue that learners' efforts are strongly shaped by competing value systems that valorize some practices over others, variations in supports available from guides, and others' recognition (and misrecognition) of their racial and class identities and perceived abilities.

As we illustrate through the case of Jerome (a pseudonym), the particular pattern of engagements and stance toward science-related pursuits emerges from a kind of "dance of agency" (Pickering, 1995) as he initiates movement toward science-related futures within a particular context that enables development toward some directions but not others, leading him to re-configure their engagements in relation to how that context responds to his initiative (see also Carlone, 2004).

\subsection{Context for the case analysis}

For the duration of the study, Jerome was a participant in a program called Pathways into Science (also a pseudonym) at a science museum in a large city in the U.S. West. The museum's program is like many others in large science museums across the country that provide learning opportunities to youth from groups that are underrepresented in science. It is funded by a variety of private foundations and individual donors. Youth participants must attend public schools in the city where the museum is located, be enrolled as a ninth or tenth grader, and commit to meeting the attendance requirements year-round and over multiple years for which the youth are eligible. The program is run as a paid internship in which youth serve as docents for the museum visitors and have opportunities to contribute to science investigations led by resident scientists.

Jerome fit the profile well of the type of youth the program seeks to serve. He had a strong interest in science and a strong work ethic that made him well suited to meet the heavy time commitments of the program. His mother was an immigrant to the United States, and during our interview with him, he identified himself as Black, which he asserts made him stand out among his peers and at the museum as different from most other people. At the time of the interview he had just completed his junior year of high school.

\subsection{Approach to case development}

Jerome was part of a larger study our team has been conducting for the past three years of youths' experience of Connected Learning, an emerging, synthetic model of interest-related learning being investigated by a network of scholars in a range of settings (Ito et al., 2013). As we defined it for this study, youth were engaged in interest-related learning if they could identify an activity they enjoyed doing, pursued it over a long period of time, and believed they were getting better at the activity over time or learning from it. The approach we took to analyzing youth learning was a case study approach, in which we focused on an interest-related pursuit as youth's participation in it transformed over time and as they moved across settings. We drew on interview data we collected from a larger study of 54 youth who were aged 13-17, and through a process of collaborative data organization, coding, representation, and analysis, aimed to illustrate the utility of taking a social practice approach to the study of learning as movement across settings.

Our interview protocol included questions that elicited youth's descriptions of their activities and purposes for participation, their current involvement in their activity, the networks (e.g. linkages and 
supports) they drew upon when participating in their activity, obstacles they experienced, and how they perceived the future as related to their participation. Informed by our theoretical orientation to learning as movement, the interviews purposefully elicited youths' perspectives on how their participation changed over time and across different settings. Because a social practice perspective encouraged a focus on youth agency in distributing their engagements, we focused on how youth themselves viewed their actions, as well as the continuities and discontinuities they experienced as they moved across the settings they traverse (see also Akkerman and Bakker, 2011).

To analyze the data, we began deductively with a set of high-level codes related to the broad outlines of social practice theory, attending specifically to how engagement in the activity transformed over time and across settings. Parent codes such as 'linkages/supports,' 'barriers,' 'possible futures,' and 'identities/roles' allowed us to get a sense of how youth characterized the many disruptions and opportunities that became more or less relevant to their lives - a central aspect of a social practice approach to analysis. The coding was used as a first step in identifying themes related to how individuals distributed their engagements across multiple settings and over time. In the analysis for this conceptual article, we focused on themes derived from codes linked to youths' experiences during their initial engagement with the activity and subsequent engagements with the activity, namely 'initial relationship to engagement' as it co-occurred with the child codes within 'reason/stance/relationship to participation' such as 'career,' 'friends,' 'academics,' 'civic engagement,' and/or 'skill building and mastery.' The focus on these codes was reflective of our desire to make sense of youths' relationship to varied structures of practice, as well as their different stances toward interest-related pursuits.

We then created data displays for each student that listed their descriptions of initial activity, history of involvement in activity, youth articulations of participation within and outside of the program, their future goals, and immediate outcomes, noting also the different settings in which activities took place. Our analysis provided strong supporting evidence that rather than linear or straightforward, youths' pathways were often characterized by a shifting and fluid distribution of engagement in a variety of settings over time. For this paper, we chose a case (Jerome) that we concluded illustrated well the agency of young people in this process.

\subsection{Jerome's initial goals for participation in the pathways program}

Jerome's story is not one of a simple pipeline into a science career that is institutionally supported and easily navigable for him. He actively worked to set up and select his involvement in science-related programs, and he benefited from access to institutions that helped him to link engagements over time between contexts. Before he first started at the science museum, he worked with another program that connected him with numerous different programs around the city that matched with his interest in science. Jerome applied to many of these programs in attempt to find a place where he could explore his interest in science and be exposed to different kinds of sciences. He also decided against another program because it was too familiar, stating, "that's a lot of people from my neighborhood, so I know them and I always like to get to know other people and see what different places and cities are like."

Consistent with Jerome's goal to expand his social network, at the beginning he experienced discontinuities between his community and the museum. He said, "It was different because I wasn't too accustomed to being around people who weren't exactly from my neighborhood or my ethnicity." Jerome experienced this new context as discontinuous with his prior context but complementary to his goals, which he linked to a sense of racial difference within the program. Over time, his sense of difference from others faded as he deepened relationships with others through retreats and a leveled role structure (e.g., youth at level one are mentored by youth at level two). As he has moved up this structure, Jerome has taken on leadership roles in the program, joining the leadership council, giving him "more of a say in the program's direction and working with others on how to improve the program." 


\subsection{Emergent patterns of engagement an stances}

A big part of Jerome's learning within the paid intern program centered on learning how to contribute to the ongoing activities of the museum. Interns' teaching was organized around "stations" connected to natural history exhibits at the museum. He had to work three days a week on the floor of the museum, which he described as "nerve-wracking" since he disliked public speaking. But he said the push helped him build his public speaking skills, and because near-peers in the program-interns one level up in the program from him - pushed him to contribute:

When we first started, they would try to encourage you to-you're at a station and you're talking about whatever your station is about and the other intern, they are more experienced, so they know what to talk about and to push you out there they will say, "Oh, Michael can tell you more about it."

He also got to take part in science investigations at the museum, where he gained a partial view of the ongoing work of scientists there. He came to realize through these experiences that he really liked working in labs with other people and coming up with a question that "you really never know what it is going to be in the end." At the same time, he developed a stance toward science that pointed away from a career in basic science. "I couldn't be a botanist," he said, and then generalized to all scientists, saying, "I see what they do here and confined to the basement or downstairs. Most scientists, they work alone and I don't really like to work alone, but I would want to do it as volunteer work or helping out whatever." Though he had opportunities to work with scientists in the laboratory, it is not clear whether he has not accompanied them to places where he might gain a fuller view of range of activities that characterize scientific practice.

Jerome did anticipate doing something science-related for his future career and continuing to volunteer in a science museum as an adult, though these pathways are not visible or directly accessible to him, either through the program or through his social network. He expressed a mix of worry and confidence about his direction:

I've never been exposed to the steps that it takes to be a doctor or physician or whatever.

So I don't know, is the workload going to be like crazy, but I've never experienced something that was like impossible. So I guess it's possible.

In addition, his map of colleges and universities was relatively incomplete, focused on highly competitive and well-known national universities like Harvard and Stanford on one end and a less competitive local public university. He believed that "it doesn't matter which school you go to, it just matters how good you do at that school," and that it's not important to get caught up in the reputation of the school.

\subsection{Support from outside the program}

Some of Jerome's confidence likely arose from the fact that Jerome is strongly supported by his family members. Jerome described his mother, grandmother, and older brother as all highly supportive of his involvement. His mother was especially supportive of Jerome's decision not to take the "sports route" his peers seemed to be on and that he saw was highly valued. She and other family members encouraged him to go his own way:

They [older brother, grandmother] just tell me to do what I feel is best and are supportive. I was on the flyer for the program the first year I was in here and my mom made like fifty copies and sent them out. My grandma has one hanging in her room and she mailed it to other family members. They're really happy and supportive in that kind of way, just happy for me in general.

Though Jerome was happy that the recognition of his accomplishments followed him home, his personal stance toward sharing his accomplishments with others was more complex. He preferred not to talk 
about them, because he saw it as too self-centered. He said, "It's weird to talk about yourself. I just do it and move on."

At the conclusion of our interview with him, we asked Jerome to characterize his identity-is he a scientist, an intern, or something else? He easily characterized himself as a "student," saying "I consider myself a student, I just feel like I'm constantly learning, not just in school, but in everyday life. In the city and just being alive..." Jerome connected his identity as a student or an everyday learner to his interaction with people. He expressed confidence in his ability, and also a compulsion to know things, which he said makes him an especially good fit to the program he was in.

\section{Discussion and conclusion}

Our analysis illustrates one way to use social practice theory to study transformations in youth participation in an interest-related pursuit over time and across settings. In Jerome's case, attending to the different stances toward participation in activity helped illuminate how he was thinking about his future. There was evidence of both continuity and discontinuity between his experience in the museum and his imagined future. As such, his interest in science may be more akin to a "line of practice" of the kind Azevedo $(2011,2013)$ describes, in which a "line" or pathway can be discerned, though participation changes significantly over time.

Jerome's opportunity to participate in and move across varied settings was central to his developing sense of future possibilities. Social practice theory helped us to see Jerome's distribution of his engagements as central to his interest development. Jerome highlighted opportunities to learn how to be a docent on the museum floor, as well as his participation in research as significant for his learning. He noted, for example, through his observation ("I see what they do here") that most of the scientists worked alone, in basements, and contrasted that with his own enjoyment of collaboration, interaction, and helping others. Although this may not be a completely accurate view of what is often highly collaborative work of scientists, this observation enabled Jerome to channel his energies where he sees the greatest alignment with what he wants to be doing in his everyday work life. In its emphasis on how youth distribute engagement across different settings, social practice theory differs from traditional "pipeline" metaphors for pathways into STEM, which tend to focus on content but not on movement across settings. This social practice analysis, which we have foregrounded in this paper, also shows that interaction with graduates of his program has already prepared him for some of the challenges that he may face in a few years. He learned from near-age peers about how challenging pre-med courses could be and the self-doubt that can creep in during that pre-med experience.

Jerome's achievements to this point represent the best of what STEM interventions seek to accomplish, in terms of broadening access to the field for someone with limited exposure to it, and cultivating deeper and more nuanced interest in the various pathways related to STEM. He has a better sense of what he wants and what he doesn't want, as well as the threats to achieving that goal. We contend that policy interventions that foreground these issues associated with linkages, networks, and practices represent a promising direction for the field. Studying and supporting those interventions requires us, however, to move beyond traditional foci of learning research and look at learning through a social practice lens. We contend that using social practice theory in the analysis of youth's learning is potentially transformative in this respect, for it highlights potential leverage points for transforming systems to enable broader participation in STEM. 


\section{Keypoints}

* A social practice theory offers a lens for interpreting interest-related learning pathways across settings and over time.

* A social practice account highlights learners' agency as they pursue diverse concerns across a range of settings, as well as existing how structures of practice constrain agency and limit access to some settings.

* A social practice account provides a more expansive framework for understanding how and when persons and practices are mutually constituted in such a way as to broaden access to STEM fields.

\section{Acknowledgments}

Funding for this research comes from the John D. and Catherine MacArthur Foundation. Any opinions, findings, and conclusions or recommendations expressed in this material are those of the author(s) and do not necessarily reflect the views of the funder.

\section{References}

Bell, P., Tzou, C., Bricker, L. A., \& Baines, A. D. (2012). Learning in diversities of structures of social practice: Accounting for how, why, and where people learn science. Human Development, 55, 269-284. DOI: $10.1159 / 000345315$.

Bricker, L. A., \& Bell, P. (2014). "What comes to mind when you think of science? The Perfumery!": Documenting science-related cultural learning pathways across contexts and timescales. Journal of Research in Science Teaching, 51(3), 260-285. DOI: 10.1002/tea.21134.

Calabrese Barton, A., \& Tan, E. (2009). Funds of knowledge, discourses and hybrid space. Journal of Research in Science Teaching, 46(1), 50-73. DOI: 10.1002/tea.20269.

Carlone, H. B. (2004). The cultural production of science in reform-based physics: Girls' access, participation, and resistance. Journal of Research in Science Teaching, 41(4), 392-414. DOI: 10.1002/tea.20006.

Cole, M., \& Engeström, Y. (2006). Cultural-historical approaches to designing for development. In J. Valsiner \& A. Rosa (Eds.), The Cambridge handbook on sociocultural psychology (pp. 484-507). New York: Cambridge University Press.

Crowley, K., Barron, B. J. S., Knutson, K., \& Martin, C. K. (in press). Interest and the development of pathways to science. In K. A. Renninger, M. Nieswandt, \& S. Hidi (Eds.), Interest in mathematics and science learning and related activity. Washington, DC: American Educational Research Association.

Dreier, O. (1997). Subjectivity and social practice. Aarhus, Denmark: Center for Health, Humanity, and Culture.

Dreier, O. (1999). Personal trajectories of participation across contexts of social practice. Outlines: Critical Social Studies, 1(1), 5-32.

Dreier, O. (2008). Psychotherapy in everyday life. New York: Cambridge University Press.

Dreier, O. (2009). Persons in structures of social practice. Theory \& Psychology, 19(2), 193-212. DOI: $10.1177 / 0959354309103539$.

Engeström, Y., \& Sannino, A. (2010). Studies of expansive learning: Foundations, findings and future challenges. Educational Research Review, 5, 1-24. DOI: 10.1016/j.edurev.2009.12.002.

Gonzales, R. G. (2011). Learning to be illegal: Undocumented youth and shifting legal contexts in the transition to adulthood. American Sociological Review, 76(4), 602-619. DOI: $10.1177 / 0003122411411901$. 
Gutiérrez, K. D. (2008). Developing sociocritical literacy in the third space. Reading Research Quarterly, 43(2), 148-164. DOI: 10.1598/RRQ.43.2.3.

Gutiérrez, K. D., Baquedano-Lopez, P., \& Tejada, C. (2000). Rethinking diversity: Hybridity and hybrid language practices in the third space. Mind, Culture, and Activity, 6(4), 286-303. DOI: $10.1080 / 10749039909524733$.

Gutiérrez, K. D., \& Vossoughi, S. (2010). Lifting off the ground to return anew: Mediated praxis, transformative learning, and social design experiments. Journal of Teacher Education, 61(1-2), 100117. DOI: $10.1177 / 0022487109347877$.

Holland, D., \& Lave, J. (2009). Social practice theory and the historical production of persons. Actio: An International Journal of Human Activity Theory (2), 1-15.

Ito, M., Gutiérrez, K. D., Livingstone, S., Penuel, W. R., Rhodes, J. E., Salen, K., Schor, J., Sefton-Green, J., $\&$ Watkins, S. C. (2013). Connected Learning: An agenda for research and design. Irvine, CA: Digital Media and Learning Research Hub.

Jefferson, A. M., \& Huniche, L. (2009). Re(searching) for persons in practice: Field-based methods for critical psychological practice research. Qualitative Research in Psychology, 6(1-2), 12-27. DOI: 10.1080/14780880902896507.

Jurow, A. S., \& Shea, M. (2015). Learning in equity-oriented scale-making projects. Journal of the Learning Sciences, 24(2), 287-307. DOI: 10.1080/10508406.2015.1004677.

Lave, J. (1996). Teaching, as learning, in practice. Mind, Culture, and Activity, 3(3), 149-164. DOI: 10.1207/s15327884mca0303_2.

Lave, J. (2012). Changing practice. Mind, Culture, and Activity, 19(2), 156-171. DOI: 10.1080/10749039.2012.666317.

Lave, J., \& McDermott, R. P. (2002). Estranged tabor learning. Outlines, 1, 19-48.

Marx, K., \& Engels, F. (1848/1998). The German ideology, including theses on Feuerbach and introduction to the critique of political economy. Amherst, NY: Prometheus Books.

McDaniel, M. A., Agarwal, P. K., Huelser, B. J., McDermott, K. B., \& Roediger III, H. L. (2011). Testenhanced learning in a middle school science classroom: The effects of quiz frequency and placement. Journal of Educational Psychology, 103(2), 399. DOI: 10.1037/a0021782.

Mørck, L. L. (2010). Expansive learning as production of community. In Learning research as a human science. Yearbook of the National Society for the Study of Education (Vol. 109, pp. 176-191). New York, NY: Teachers College Record.

Mørck, L. L., \& Huniche, L. (2006). Critical psychology in a Danish context. Annual Review of Critical Psychology, 5.

Nissen, M. (2005). The subjectivity of participation: Sketch of a theory. International Journal of Critical Psychology, 15, 151-179.

O'Connor, K., \& Allen, A.-R. (2010). Learning as the organizing of social futures. In Learning research as a human science. National Society for Studies in Education, 109(1), 160-175.

Penuel, W. R. (2016). Studying science and engineering learning in practice. Cultural Studies of Science Education, 11(1), 89-104. DOI: 10.1007/s11422-014-9632-x.

Pickering, A. (1995). The mangle of practice: Time, agency, and science. Chicago, IL: University of Chicago Press.

Polman, J. L., \& Miller, D. (2010). Changing stories: Trajectories of identification among African American youth in a science outreach apprenticeship. American Educational Research Journal, 47(4), 879-918. DOI: $10.3102 / 0002831210367513$.

Varenne, H., \& McDermott, R. P. (1998). Successful failure: The school America builds. New York: Westview Press.

Vygotsky, L. S. (1934/1978). Mind in society: The development of higher psychological processes. Cambridge, MA: Harvard University Press.

Vygotsky, L. S. (1987). Thought and language (A. Kozulin, Trans.). Cambridge: Cambridge University Press. 